\title{
Topical vancomycin in combination with perioperative antibiotics and tight glycemic control helps to eliminate sternal wound infections
}

\author{
Harold L. Lazar, MD, ${ }^{a}$ Ara Ketchedjian, MD, ${ }^{a}$ Miguel Haime, MD, ${ }^{a}$ Karl Karlson, MD, ${ }^{a}$ and \\ Howard Cabral, $\mathrm{PhD}^{\mathrm{b}}$
}

Objective: This study was undertaken to determine whether topical vancomycin would further reduce the incidence of sternal infections in the presence of perioperative antibiotics and tight glycemic control.

\begin{abstract}
Methods: A total of 1075 consecutive patients undergoing cardiac surgery from December 2007 to August 2013 receiving topical vancomycin $(2.5 \mathrm{~g}$ in $2 \mathrm{~mL}$ of normal saline $)$ applied as a slurry to the cut edges of the sternum were compared with 2190 patients from December 2003 to November 2007 who did not receive topical vancomycin. All patients received perioperative antibiotics (cefazolin $2 \mathrm{~g}$ intravenously every 8 hours and vancomycin $1 \mathrm{~g}$ intravenously every 12 hours) on induction of anesthetic and continuing for 48 hours; and intravenous insulin infusions to maintain serum blood glucose level between 120 and $180 \mathrm{mg} / \mathrm{dL}$.
\end{abstract}

Results: Patients receiving topical vancomycin had less superficial sternal infections $(0 \%$ vs $1.6 \% ; P<.0001)$, deep sternal infections $(0 \%$ vs $0.7 \% ; P=.005)$, any type of sternal infection $(0 \%$ vs $2.2 \% ; P<.0001)$ and significantly less sternal infections of any type in patients with diabetes mellitus $(0 \%$ vs $3.3 \% ; P=.0004)$.

Conclusions: Topical vancomycin applied to the sternal edges, in conjunction with perioperative antibiotics and tight glycemic control, helps to eliminate wound infections in cardiac surgical patients. (J Thorac Cardiovasc Surg 2014;148:1035-40)

Although the incidence of sternal wound infections has decreased to $1 \%$ to $4 \%$ of all cardiac surgical patients, they are associated with increased morbidity and mortality and decreased long-term life expectancy. ${ }^{1-4}$ Sternal wound infections prolong hospital stay and are now publically reported. ${ }^{5,6}$ They can raise hospital costs by as much as US\$62,000. ${ }^{7}$ The US Center for Medicine and Medicaid services no longer reimburse hospital costs incurred in the treatment of deep sternal wound infections after coronary artery bypass graft $(\mathrm{CABG})$ surgery. ${ }^{8}$

Several methods have been successful in decreasing the incidence of sternal wound infections. These include the use of perioperative antibiotics, glycemic control with intravenous insulin infusions, and the avoidance of bone wax. ${ }^{9-13}$ These therapies have decreased, but have not eliminated sternal wound infections.

Previous studies have shown that topical antibiotics, used in a dry or powdered form, achieve much higher local

From the Division of Cardiac Surgery, ${ }^{\mathrm{a}}$ Boston Medical Center and the Boston University School of Medicine, Boston, Mass; and Department of Biostatistics, ${ }^{\mathrm{b}}$ Boston University School of Public Health, Boston, Mass.

Disclosures: Harold L. Lazar has received funding from Eli Lilly, Inc. All other authors have nothing to disclose with regard to commercial support.

Read at the 94th Annual Meeting of The American Association for Thoracic Surgery, Toronto, Ontario, Canada, April 26-30, 2014.

Received for publication April 4, 2014; revisions received June 17, 2014; accepted for publication June 27, 2014

Address for reprints: Harold L. Lazar, MD, Division of Cardiac Surgery, Boston Medical Center, 88 East Newton St, Boston, MA 02118 (E-mail: harold.lazar@bmc. org).

$0022-5223 / \$ 36.00$

Copyright (c) 2014 by The American Association for Thoracic Surgery

http://dx.doi.org/10.1016/j.jtcvs.2014.06.045 wound concentrations than are possible with systemic antibiotics and that this high concentration persists for several hours after the closure of the wound. ${ }^{14}$ Vander Salm and colleagues ${ }^{15}$ found that using topical vancomycin resulted in a significant decrease in sternal wound infections in patients undergoing cardiac surgical procedures. This study was therefore undertaken to determine whether topical vancomycin would further reduce the incidence of sternal wound infections in the presence of perioperative antibiotics and tight glycemic control.

\section{METHODS}

A total of 3265 consecutive patients undergoing cardiac surgical procedures using a full-length median sternotomy incision at the Boston Medical Center from December 2003 to August 2013 were included in the study. Institutional Review Board approval was obtained and the need for consent was waived because the study design was retrospective and relevant identifiers were stripped from the data.

\section{Study Groups}

All patients received perioperative antibiotics, consisting of cefazolin ( $2 \mathrm{~g}$ intravenously [IV] every 8 hours) and vancomycin ( $1 \mathrm{~g}$ IV every 12 hours) on induction of anesthetic and continuing for 48 hours after surgery. Intravenous insulin infusions were used starting at the time of induction of anesthetic and continuing for 24 hours to maintain serum glucose values between 120 and $180 \mathrm{mg} / \mathrm{dL} .{ }^{10}$ From December 2007 to August 2013, 1075 consecutive patients received topical vancomycin. In these patients, after the median sternotomy, a slurry consisting of $2.5 \mathrm{~g}$ of powdered vancomycin (Eli Lilly Inc, Indianapolis, Ind) diluted in 2 $\mathrm{mL}$ of normal saline was prepared in the operative field and applied to both edges of the cut sternum. The same process was performed immediately before rewiring the sternum. This group of patients was compared with a cohort of 2190 patients from December 2003 to November 2007 in whom topical vancomycin was not used. These 2 


$$
\begin{aligned}
& \text { Abbreviations and Acronyms } \\
& \text { CABG }=\text { coronary artery bypass graft } \\
& \text { CHF }=\text { congestive heart failure } \\
& \text { CPB }=\text { cardiopulmonary bypass } \\
& \text { ITA }=\text { internal thoracic artery } \\
& \text { MI }=\text { myocardial infarction } \\
& \text { PVD }=\text { peripheral vascular disease } \\
& \text { STS }=\text { Society of Thoracic Surgeons }
\end{aligned}
$$

time periods were chosen because there were no changes in the preoperative, intraoperative, or postoperative protocols for patients undergoing cardiac surgery.

\section{Surgical Technique}

Surgical techniques were identical for both groups. All procedures were performed on heparin-bonded cardiopulmonary bypass circuits with a membrane oxygenator. The left internal thoracic artery (ITA) was harvested as a pedicle graft in all patients with a left anterior descending lesion greater than $50 \%$. Bilateral ITAs were used at the discretion of the individual surgeon. The sternum was routinely closed with 4 figure-of-eight sternal cable wires. The fascia, subcutaneous layer, and skin layer were closed with running, monofilament, absorbable sutures. Antibiotic impregnated sutures were not used in any patient.

\section{Definition of Sternal Infections}

The criteria used for the definition and classification of sternal wound infections were according to the Centers for Disease Control and Prevention. ${ }^{16}$ Depths 1 and 2 were defined as a superficial infectious process limited to the subcuticular and subcutaneous layers with no involvement of the sternal bone. Depths 3 and 4, which involved the sternal bone or wires and collections beneath the sternum, were considered deep infections. A wound was considered infected only if a positive culture for an organism was obtained. Reported infections included all infections that developed within 1 year of surgery.

\section{Risk Factors}

Patient risk factors were defined according to the Society of Thoracic Surgeons (STS) Adult Cardiac Surgery Database, ${ }^{17}$ These included those factors that have been shown to be associated with a high risk for postoperative wound infection and included age, weight, diabetes mellitus, renal failure, congestive heart failure (CHF), peripheral vascular disease (PVD), female gender, chronic obstructive lung disease, cardiogenic shock, myocardial infarction (MI), ejection fraction, urgency of surgery, need for steroids, and smoking. ${ }^{18}$

\footnotetext{
Statistical Analysis

Data are presented as absolute values, percentages, and the mean \pm standard deviation. The Fisher exact test and $\chi^{2}$ test were used to test statistical significance for the incidence of sternal wound infections between the groups. The small incidence of wound infections in the total cohort of patients did not allow for meaningful multivariable analyses using models for binary outcomes. Therefore, a propensity-matched score using a greedy matching algorithm was computed to reduce the selection bias due to the retrospective nature of the study. The variables used for propensity score matching included ejection fraction, age, CHF, PVD, endocarditis, diabetes, type of surgery, urgency of surgery, smoking, previous MI, preoperative steroids, preoperative creatinine, preoperative weight, crossclamp time, and cardiopulmonary bypass (CPB) time. Analyses were performed using SAS version 9.2 software (SAS Institute, Inc, Cary, NC).
}

\section{RESULTS}

The results are summarized in Tables 1 to 3 .

Patient profiles are reviewed in Table 1. There was no difference between the groups in age, gender, the incidence of an MI, CHF, diabetes mellitus, PVD, chronic obstructive lung disease, the need for permanent dialysis, weight, serum creatinine level, or the urgency of surgery. Patients receiving topical vancomycin were more likely to have been active smokers $(29 \%$ vs $19 \% ; P<.0001)$ and undergone surgery for endocarditis ( $5 \%$ vs $3 \% ; P=.002)$. Ejection fraction was slightly higher in the topical vancomycin group $(53.1 \% \pm 12.5 \%$ vs $51.5 \% \pm 13.7 \% ; P=.001)$.

Most patients underwent isolated CABG surgery (Table 2). There was a lower incidence of isolated CABG surgery and a higher incidence of isolated valve procedures in the patients receiving topical vancomycin. There was no difference in the incidence of the use of a single ITA ( $61 \%$ vancomycin vs $63 \%$ no vancomycin) or a double ITA (3\% vancomycin vs $3 \%$ no vancomycin). The crossclamp times were $72 \pm 33$ minutes with no vancomycin versus $67 \pm 28$ minutes with vancomycin $(P<.001)$ and the CPB times were $113 \pm 40$ minutes with no vancomycin versus $105 \pm$ 48 minutes with vancomycin $(P<.001)$.

The incidence of sternal infections is shown in Table 3. Patients receiving topical vancomycin had no superficial infections ( $0 \%$ vs $1.6 \% ; P<.0001)$, no deep sternal infection $(0 \%$ vs $0.7 \% ; P=.005)$, or any type of sternal infection $(0 \%$ vs $2.3 \% ; P<.0001)$ compared with the patients in whom topical vancomycin was not used. This was particularly evident in patients with diabetes mellitus; patients in this group receiving topical vancomycin had no infections $(0 \%)$ compared with an incidence of $3.3 \%$ in patients not receiving topical vancomycin $(P=.0004)$.

For the 444 patients receiving topical vancomycin who were propensity matched to 444 patients not receiving vancomycin, the estimated difference of any sternal infection was $1.1 \%$. This was statistically significant $(P=.02)$ in those analyses that accounted for the lack of statistical independence imposed by the matching.

\section{DISCUSSION}

Our results have shown that topical vancomycin, in combination with perioperative antibiotics and tight glycemic control eliminated both superficial and deep sternal wound infections in patients undergoing a median sternotomy during cardiac surgery. Both groups of patients had a similar incidence of those risk factors that were shown by Fowler and colleagues to predict the incidence of postoperative wound infections. ${ }^{18}$ Our findings are in keeping with other studies that have shown that topical vancomycin reduces sternal wound infections. Vander Salm and colleagues ${ }^{15}$ found that the use of topical vancomycin prepared as a slurry, similar to our technique, in conjunction with 
TABLE 1. Patient profiles

\begin{tabular}{|c|c|c|c|}
\hline Variable & $\begin{array}{c}\text { Topical } \\
\text { vancomycin }\end{array}$ & $\begin{array}{c}\text { No } \\
\text { vancomycin }\end{array}$ & $\begin{array}{c}P \\
\text { value } \\
\end{array}$ \\
\hline Number & 1075 & 2190 & - \\
\hline Age (y) & $65.7 \pm 11.6$ & $65.9 \pm 12.7$ & .66 \\
\hline Male/female & $741 / 334$ & $1489 / 701$ & .59 \\
\hline Current smoker, $\mathrm{n}(\%)$ & $312(29)$ & $416(19)$ & $<.0001$ \\
\hline $\begin{array}{l}\text { Previous myocardial } \\
\text { infarction/heart failure, } \mathrm{n}(\%)\end{array}$ & $365(34)$ & $700(32)$ & .25 \\
\hline Preoperative steroids, $\mathrm{n}(\%)$ & $32(3)$ & $43(2)$ & .07 \\
\hline Diabetes mellitus, n (\%) & $365(34)$ & $722(33)$ & .57 \\
\hline Insulin diabetes, $\mathrm{n}(\%)$ & $128(35)$ & $238(33)$ & .49 \\
\hline Ejection fraction, $\mathrm{n}(\%)$ & $53.1 \pm 12.5$ & $51.5 \pm 13.7$ & .001 \\
\hline Permanent dialysis, $\mathrm{n}(\%)$ & $21(2)$ & $67(3)$ & .07 \\
\hline Endocarditis, n (\%) & $55(5)$ & $65(3)$ & .002 \\
\hline Preoperative stroke, n (\%) & $150(14)$ & $306(14)$ & .99 \\
\hline Peripheral vascular disease, $\mathrm{n}(\%)$ & $86(8)$ & $175(8)$ & .99 \\
\hline Cardiogenic shock, n (\%) & $7(0.6)$ & $13(0.6)$ & .84 \\
\hline $\begin{array}{l}\text { Chronic obstructive pulmonary } \\
\text { disease, } \mathrm{n}(\%)\end{array}$ & $96(9)$ & $240(11)$ & .07 \\
\hline \multicolumn{4}{|l|}{ Surgery status } \\
\hline Elective, n (\%) & $451(42)$ & $941(43)$ & \\
\hline Urgent, n $(\%)$ & $602(56)$ & $1204(55)$ & .86 \\
\hline Emergency, n (\%) & $22(2)$ & $45(2)$ & \\
\hline Emergency salvage, n (\%) & $0(0)$ & $0(0)$ & \\
\hline Weight $(\mathrm{kg})$ & $84.3 \pm 19.2$ & $83.4 \pm 18.8$ & .20 \\
\hline Creatinine $(\mathrm{mg} / \mathrm{dl})$ & $1.10 \pm 0.76$ & $1.11 \pm 0.97$ & .77 \\
\hline
\end{tabular}

Data are presented as the absolute values, $\%$, or the mean \pm standard deviation.

perioperative systemic antibiotics, reduced the incidence of sternal wound infections from $3.6 \%$ to $0.45 \%(P=.02)$ in a blinded, prospective, randomized trial involving 416 patients. Arruda and colleagues, ${ }^{19}$ in a retrospective study involving 1020 patients receiving topical vancomycin, reduced the incidence of sternal wound infections to $0.49 \%$. Ozzan and colleagues ${ }^{20}$ studied the effects of topical vancomycin in a rat model in which the sternum was inoculated with methicillin-resistant Staphylococcus aureus. After 7 days, the quantity of organisms in the mediastinal bone was significantly decreased in those animals treated with a combination of systemic IV and topical vancomycin in contrast to those animals that received only systemic IV antibiotics.

TABLE 2. Procedures performed

\begin{tabular}{lccc}
\hline \multicolumn{1}{c}{ Variable } & $\begin{array}{c}\text { Topical } \\
\text { vancomycin }\end{array}$ & $\begin{array}{c}\text { No } \\
\text { vancomycin }\end{array}$ & $\boldsymbol{P}$ value \\
\hline Number & 1075 & 2190 & - \\
CABG, n $(\%)$ & $591(55)$ & $1270(58)$ & \\
CABG + valve, n (\%) & $130(12)$ & $263(12)$ & .002 \\
Isolated valve, n (\%) & $322(30)$ & $547(25)$ & \\
Valve + other, n (\%) & $32(3)$ & $110(5)$ & \\
Single ITA, n $(\%)$ & $656(61)$ & $1400(63)$ & .23 \\
Bilateral ITA, n $(\%)$ & $21(3)$ & $46(3)$ & \\
\hline
\end{tabular}

Data are presented as the absolute values and \%. CABG, Coronary artery bypass graft; ITA, internal thoracic artery.
TABLE 3. Incidence of sternal infections

\begin{tabular}{lccc}
\hline \multicolumn{1}{c}{ Variable } & $\begin{array}{c}\text { Topical } \\
\text { vancomycin }\end{array}$ & $\begin{array}{c}\text { No } \\
\text { vancomycin }\end{array}$ & $\begin{array}{c}\boldsymbol{P} \\
\text { value }\end{array}$ \\
\hline Number & 1075 & 2190 & - \\
Superficial sternal infection, n (\%) & $0(0)$ & $34(1.6)$ & $<.0001$ \\
Deep sternal infection, n (\%) & $0(0)$ & $16(0.7)$ & .005 \\
All sternal infections, n (\%) & $0(0)$ & $50(2.3)$ & $<.0001$ \\
All sternal infections among & $0(0)$ & $24(3.3)$ & .0004 \\
$\quad$ patients with diabetes & & & \\
$\quad$ mellitus (\%) & & & \\
Data are presented as the absolute values and \%. & &
\end{tabular}

Concerns have been raised that the use of topical vancomycin may result in persistently high levels of this antibiotic, which may lead to the emergence of vancomycin-resistant organisms. ${ }^{21}$ In a previous study involving 36 patients undergoing a median sternotomy during cardiac surgery, ${ }^{22}$ we sought to determine whether the use of topical vancomycin, applied as a slurry immediately after sternotomy and before sternal wiring as in this study, would result in increased serum vancomycin levels 6 days after surgery. Serum vancomycin levels were measured on the evening of surgery and on the sixth postoperative day. There was a significant decrease in serum vancomycin levels from $11.5 \pm 1.9 \mathrm{mg} / \mathrm{mL}$ to $2.12 \pm 0.19 \mu \mathrm{g} / \mathrm{mL}$ $(P<.0001)$. No patient developed a sternal wound infection. Furthermore, at 1-year follow-up, topical vancomycin did not potentiate the emergence of drug-resistant infections or contribute to postoperative renal toxicity.

One theory for the beneficial effects of topical vancomycin is that it may promote sternal union and accelerate the healing process making it less likely for bacteria to colonize. We did not observe any evidence of sternal instability or nonunion in patients treated with vancomycin, even those with diabetes mellitus. This potential mechanism may be similar to that seen with gelatin-thrombin sealant, which acts as an osteoinductive protein that stimulates fibroblast growth, ${ }^{23}$ This provides a matrix for osteoblast translocation, thus promoting bone formation, thereby reducing the risk of sternal nonunion and osteomyelitis. ${ }^{24}$ In addition, the antimicrobial effect of vancomycin minimizes bacterial ingrowth and inoculation of bone.

Topical vancomycin has also been shown to decrease wound infections in other groups of patients undergoing surgical procedures, including spinal surgery, ${ }^{25}$ neurosurgery involving cranioplasty, ${ }^{26}$ dental procedures involving bone implants, ${ }^{27}$ and to reduce the incidence of preperitoneal pocket infections in patients undergoing implantation of a left ventricular assist device. ${ }^{28}$ There are several advantages to the use of topical vancomycin. It is easy to prepare and handle, and is relatively inexpensive. It has no systemic or local adverse effects. It provides effective hemostasis for bleeding from the sternum because it readily adheres to cut bone surfaces or open bone fractures. It also provides 
bacteriostatic and bacteriocidal protection against grampositive organisms that normally cause infections such as Staphylococcus and Streptococcus.

Our study has several limitations. It is retrospective, from a single center, and involves separate time periods. However, the sample size is large and there were no changes in perioperative protocols involving antibiotics, surgical techniques, or postoperative care during the study period. Propensity matching was used to ensure that the risk factors known to cause sternal infections were evenly matched between the groups. Although the crossclamp and CPB times were statistically longer in the no vancomycin group, the differences are small (5 minutes crossclamp time and 8 minutes $\mathrm{CPB}$ time). Furthermore, our propensity-matched subset analysis, which took into account crossclamp and CPB times, showed a $1.1 \%$ difference in any sternal infections, which was statistically different $(P=.02)$.

We conclude that topical vancomycin in combination with perioperative antibiotics and tight glycemic control eliminates sternal infections in patients undergoing cardiac surgical procedures. Consideration should be given to using topical vancomycin in all patients undergoing a median sternotomy.

\section{References}

1. Toumpoulis IK, Anagnostopoulos CE, Derose JJ Jr, Swistel DG. The impact of deep sternal wound infection on long-term survival after coronary artery bypass grafting. Chest. 2005; 127:464-71.

2. Graf K, Ott E, Vonberg RP, Kuehn C, Haverich A, Chaberny IF. Economic aspects of deep sternal wound infections. Eur J Cardiothorac Surg. 2010;37:893-6.

3. Braxton JH, Marrin CA, McGrath PD, Ross CS, Morton JR, Norotsky M, et al. Northern New England Cardiovascular Disease Study Group. Mediastinitis and long-term survival after coronary artery bypass graft surgery. Ann Thorac Surg. 2000;70:2004-7.

4. Milano CA, Kesler K, Archibald N, Sexton DJ, Jones RH. Mediastinitis after coronary artery bypass graft surgery. Risk factors and long-term survival. Circulation. 1995;92:2245-51.

5. Nero DC, Lipp MJ, Callahan MA. The financial impact of hospital-acquired conditions. J Health Care Finance. 2012;38:40-9.

6. Speir AM, Kasirajan V, Barnett SD, Fonner E Jr. Additive costs of postoperative complications for isolated coronary artery bypass grafting patients in Virginia. Ann Thorac Surg. 2009;88:40-6.

7. Ferris TG, Torchiana DF. Public release of clinical outcomes data-online CABG report cards. $N$ Engl J Med. 2010;363:1593-5.

8. Centers for Medicare \& Medicaid Services. Hospital-acquired conditions (present on admission indicator). Available at: http://www.cms.hhs.gov/Hospital AcqCond/. Accessed July 21, 2014.

9. Edwards FH, Engelman RM, Houck P, Shahian DM, Bridges CR. Society of Thoracic Surgeons. The Society of Thoracic Surgeons practice guideline series: antibiotic prophylaxis in cardiac surgery. Part I: duration. Ann Thorac Surg. 2006;81:397-404.

10. Lazar HL, Chipkin SR, Fitzgerald CA, Bao Y, Cabral H, Apstein CS. Tight glycemic control in diabetic coronary artery bypass graft patients improves perioperative outcomes and decreases recurrent ischemic events. Circulation. 2004; 109:1497-502.

11. Zerr KJ, Furnary AP, Grunkemeier GL, Bookin S, Kanhere V, Starr A. Glucose control lowers the risk of wound infection in diabetics after open heart operations. Ann Thorac Surg. 1997;63:356-61.

12. Nelson DR, Buxton TB, Luu QN, Rissing JP. The promotional effect of bone wax on experimental Staphylococcus aureus osteomyelitis. J Thorac Cardiovasc Surg. 1990;99:977-80.

13. Wellisz T, Armstrong JK, Cambridge J, An YH, Wen X, Kang Q, et al. The effects of a soluble polymer and bone wax on sternal healing in an animal model. Ann Thorac Surg. 2008;85:1776-80.
14. Halasz NA. Wound infection and topical antibiotics: the surgeon's dilemma. Arch Surg. 1977;112:1240-4.

15. Vander Salm TJ, Okike ON, Pasque MK, Pezzella AT, Lew R, Traina V, et al. Reduction of sternal infection by application of topical vancomycin. J Thorac Cardiovasc Surg. 1989;98:618-22.

16. Mangram AJ, Horan TC, Pearson ML, Silver LC, Jarvis WR. Guideline for prevention of surgical site infection, 1999. Hospital Infection Control Practices Advisory Committee. Infect Control Hosp Epidemiol. 1999;20:250-78.

17. Filardo G, Hamilton C, Grayburn PA, Xu H, Hebeler RF Jr, Hamman B. Established preoperative risk factors do not predict long-term survival in isolated coronary artery bypass grafting patients. Ann Thorac Surg. 2012;93:1943-8.

18. Fowler VG Jr, O'Brien SM, Muhlbaier LH, Corey GR, Ferguson TB, Peterson ED. Clinical predictors of major infections after cardiac surgery. Circulation. 2005;112(9 Suppl):I358-65.

19. Arruda MVF, Braile DM, Joaquim MR, Suzuki FA, Alves RH. The use of the vancomycin paste for sternal hemostasis and mediastinitis prophylaxis [in Portuguese]. Rev Bras Cir Cardiovasc. 2008;23:35-9.

20. Ozcan AV, Demir M, Onem G, Goksin I, Baltalarli A, Topkara VK, et al. Topical versus systemic vancomycin for deep sternal wound infection caused by methicillin-resistant Staphylococcus aureus in a rodent experimental model. Tex Heart Inst J. 2006;33:107-10.

21. Smith TL, Pearson ML, Wilcox KR, Cruz C, Lancaster MV, Robinson-Dunn B, et al. Emergence of vancomycin resistance in Staphylococcus aureus. Glycopeptide-Intermediate Staphylococcus aureus Working Group. N Engl J Med. 1999;340:493-501.

22. Lazar HL, Barlam T, Cabral H. The effect of topical vancomycin applied to sternotomy incisions on postoperative serum vancomycin levels. J Card Surg. 2011; 26:461-5.

23. Abiraman S, Varma HK, Umashankar PR, John A. Fibrin glue as an osteoinductive protein in a mouse model. Biomaterials. 2002;23:3023-31.

24. Zhang L, Wang P, Mei S, Li C, Cai C, Ding Y. In vivo alveolar bone regeneration by bone marrow stem cells/fibrin glue composition. Arch Oral Biol. 2012;57: 238-44.

25. Chiang HY, Herwaldt L, Schweizer M. Effectiveness of local vancomycin powder to decrease surgical site infections: a meta-analysis. Spine J. 2014;14:397-407.

26. Molinari RW, Khera OA, Molinari WJ 3rd. Prophylactic intraoperative powdered vancomycin and postoperative deep spinal wound infection: 1,512 consecutive surgical cases over a 6-year period. Eur Spine J. 2012;21(Suppl 4):S476-82.

27. Ikeda H, Kurisu K, Kihira K. Vancomycin ointment for MRSA infection at a cranioplasty site. Ann Pharmacother. 2004;38:70-2.

28. Morgan JA, John R, Rao V, Weinberg AD, Lee BJ, Mazzeo PA, et al. Bridging to transplant with the HeartMate left ventricular assist device: the Columbia Presbyterian 12-year experience. J Thorac Cardiovasc Surg. 2004;127:1309-16.

\section{Discussion}

Dr Thomas J. Vander Salm (Salem, Mass). Thank you, Harold, and congratulations for a very important paper.

In 1981, we replaced bone wax with a mixture of topical thrombin, powdered gel foam, and vancomycin applied to the cut sternal edges. In 1989, we published a study in the Journal of Thoracic and Cardiovascular Surgery on 416 patients assigned to with 2 arms, 1 of which contained the vancomycin in the aforementioned mixture, and the other that did not. We had a 7 -fold reduction in infection in the vancomycin arm, and we have used it ever since. In our last 2000 patients, we had 1 sternal or mediastinal infection. I'm delighted to see the results of this much larger study in which the vancomycin arm had no infection.

I have 3 questions for you. You address the drawbacks in your manuscript of this being a retrospective study with 2 arms being consecutive rather than simultaneous. Do you think it ethically feasible to conduct this as a randomized or a prospective study?

Dr Lazar. Well, first of all, thank you, Dr Vander Salm, for coming up here and discussing this paper. A lot of this is based on your initial findings.

I think that the data from this study and from your previous studies as well as those of others are so convincing that to try to 
do a prospective randomized study would be unethical and would not give us any more data that we already have.

Dr Vander Salm. I was hoping you would give that answer.

Your dose of vancomycin applied to the sternum was 10 times what we have used and you use it twice. How did you arrive at that dose and should we switch?

Dr Lazar. The doses of vancomycin used in all the papers have varied. In your report, you used $250 \mathrm{mg}$. Others have used $1 \mathrm{~g}$ in 2 $\mathrm{mL}$ of normal saline with excellent results. Recently, Filardo from Baylor reported using $2 \mathrm{~g}$ and $2 \mathrm{~mL}$ of normal saline.

There is actually a patent on powdered vancomycin in which the authors have reported 1 to $3 \mathrm{~g}$ per $2 \mathrm{~mL}$ of normal saline. We derived our dose from another institution that was using it, and that's why we did the subanalysis in a group of 35 to 40 patients, to show that even at that dose, there was no significant increase in vancomycin levels.

I can say that the more you use, the more it has a consistency that allows you to spread it on the sternum. And I noticed that in your study, you also used a topical thrombin gel, which gives it more of a consistency.

Dr Vander Salm. And, finally, I note that you close your median sternotomies with figure-of-eight cables as do we. The orthopedic literature gives very convincing evidence of increased susceptibility to infection at fracture sites when there is instability.

Do you believe, as we do, that the figure-of-eight cables markedly increase stability of the sternotomy and thereby account for some of your good results?

Dr Lazar. We also favor the use of the cables, and we've been using them since 1999. In the earlier group, we did have wound infections with the cables. I think the advantage of the cables is that, in more fragile sternums, it does give you more of a feeling of stability without overtightening the sternum. The cables don't cut through.

But in those patients who had infections earlier that had cables, we actually had to take the cables out, whereas if it is a superficial infection with a wire, we can leave the wire in.

But your point is very well taken, and sternal stability is very important. And in this latter group of patients in whom I used the vanco paste, as opposed to what we saw before, we did not see any evidence of any sternal instability. There was no nonunion.

One theory as to why vanco paste works is that it incites an inflammatory response that probably increases fibroblast formation. This has been studied in basic science models. I think this tends to make the bone stronger and sturdier and decreases the space for bacteria to grow.

I think it promotes sternal healing, and at the same time acts as a bactericidal agent.

Dr Irene J. Cybulsky (Hamilton, Ontario, Canada). We recently reviewed antibiotic use at our center in Hamilton, and our infection control people are quite concerned about dosing. Having reviewed the Society of Thoracic Surgeons' articles about antibiotic use, I wonder if you could comment on why you used both vancomycin and Ancef intravenously, whether you used the current recommendation of $2 \mathrm{~g}$ of Ancef and $3 \mathrm{~g}$ for bigger people, and why you feel that you need to monitor vanco levels for 6 days when most perioperative therapy need not be more than a maximum of 48 hours.

Dr Lazar. There are a number of parts to your question.
First, the title of the slide was eliminates, and I think that if you really want to eliminate, and I mean zero percent, no infections, I think you have to go with perioperative antibiotics and tight glycemic control and the use of the vanco paste. I would be a little leery about trying to cut back on 1 component because I think since 2007 we haven't seen a single wound infection on the service.

Dr Cybulsky. So just to follow up about your glycemic control, we recently audited that, and we have good intravenous control when we use the drip. But then as soon as the patients leave the intensive care unit and go to the ward, control goes out of control.

So I wonder if you can comment on the duration of your intravenous therapy and how long you monitored good glycemic control. Did you have it ongoing for 6 days?

Dr Lazar. Our protocol is that they all receive intravenous glycemic control starting in the operating room and for the time that they're in the intensive care unit.

We actually have a group of endocrinologists, a glycemic control monitoring group, who then follow them once they're off the drip. So when they leave the intensive care unit, they're off the drip. They then go with a short-acting insulin agent, and their glucose levels are monitored until the time they go home.

But the most intensive monitoring occurs in the operating room in the first 24 hours after surgery and while they're in the intensive care unit. We think that that's probably the most vulnerable time.

Dr John S. Ikonomidis (Charleston, SC). Harold, congratulations on a terrific study with fantastic and really practice-changing results.

I don't know if I missed it, but when you showed the slide on the incidence of infections, did you include superficial wound infections as well?

Dr Lazar. Yes.

Dr Ikonomidis. So you're saying since 2007, you haven't seen even a single superficial wound infection with this protocol?

Dr Lazar. That's true. I don't think it's because we're better surgeons or our techniques are better. I really do think it's the vancomycin.

Dr Ikonomidis. And the second question is that considering our knowledge about the anatomy of the internal thoracic arteries and what happens to the vascularization of the sternum when they're taken down leads me to wonder whether you were able to demonstrate a difference in vancomycin levels in patients who had single mammaries, bilateral mammaries, or skeletonized mammaries. I wonder if you could comment on that.

Dr Lazar. We don't have a large experience with bilateral mammaries. But I can tell you that even with bilateral mammaries, at least in the last 7 years, we haven't seen any infections.

As far as the diabetics are concerned, in all the patients who had their levels measured, they all went back down to subtherapeutic levels.

Dr Ani C. Anyanwu (New York, NY). I have no disclosures. Given that, I can understand how you can have a lack of gram-positive infections with vancomycin, but I find it hard to understand how you don't see gram-negatives too. And I would argue that the results you see are not because of vancomycin. There is something else you are doing.

And my question to you is if everyone in this audience and every surgeon at this meeting started using vancomycin paste, do you really think we would eliminate sternal wound infections? 
Dr Lazar. The answer to your question is yes.

And the second part to your question is that we have operated on a number of patients in this group with endocarditis due to gramnegative organisms. I have not seen any infections.

Dr Charles M. Geller (New York, NY). My question is actually very similar to Dr Anyanwu's. A number of institutions of late have been reporting an increased incidence of gram-negative as well as antibiotic-resistant organism sternal wound infections, especially in diabetic patients.
Do you feel that the more widespread use of topical vancomycin could contribute to this phenomenon as opposed to actually eliminating sternal wound infection?

Dr Lazar. No, I disagree. I know a lot of people are using this. They just haven't reported their results.

I find that even our trauma service has used it on trauma patients and open thoracotomies and wound closures, our orthopedic surgeons are using it for their implants and putting it around bone surfaces. They haven't reported their results, but they have seen no infections. 